\title{
Bauhaus: Crítica al saber sacralizado
}

\author{
Gustavo Valdés*
}

\section{Resumen / De las incertezas al tiempo subjetivo}

El autor propone desmontar la mitología que sacraliza la Bauhaus, con decisiva influencia hoy en el Diseño Gráfico, para desmantelar la significación de la Escuela en el desarrollo teórico y práctico de la disciplina.

Canonizada, fetichizada, la Bauhaus debe ser historizada más que invocada o exorcizada. La propuesta es situarla en un análisis crítico dentro del contexto histórico que le dio origen para lograr la remisión de sus determinaciones. La importación del modelo Bauhaus al campo del Diseño Gráfico argentino y la función legitimadora del mismo en la nueva profesión, devienen en una barrera para el surgimiento de perfiles genuinos.

\section{Descriptores}

Bauhaus / Comunicación / Diseño gráfico / Mito / Modernismo / Nacional-socialismo

\section{Summary / Bauhaus: critic to the sacred knowledge}

The author proposes to knock down the mythology that mades sacred the Bauhaus, with a decisive influence in the today Graphic Design to demolish the meaning of the School in the theoretical and practical development of the discipline.

Canonized, mades fetishism, the Bauhaus must be place in the history more than invoked or exorcised.

The purpose is to place it in a critical analysis into the historic context, that has given the origin to get the forgiveness of its determinations.

The importance of the Bauhaus model in the argentine Graphic Design and the legitimating function of it in the new profession, in a barrier at the arising of the genuine profiles.

\section{Resumo / Bauhaus: Critica ao saber sacralizado}

O autor propõe desarrumar a mitologia que sacraliza Bahaus, com influência decisiva hoje no desenho gráfico para desmantelar a significação da escola no desenvolvimento teórico e pratico da disciplina.

Canonizado, feito fetiche, a Bauhaus deve ser historiada mas do que invocada ou exorcismada. A proposta é situá-la em uma analise critica no contexto histórico que lhe deu origem para atingir a remissão das suas determinações.

A importação do modelo Bauhaus ao campo do desenho gráfico Argentino e a função legitimadora dele na nova profissão, tornam-se uma barreira para o surgimento de perfis genuínos.

El "hacer" -es decir la intensa práctica pedagógica y productiva de la Bauhaus (Weimar 1919 / Dessau 1932), no obstante ser la expresión "moderna" del racionalismo cartesiano y del humanismo de la llustración, terminó -por complejos factores políticoculturales - convertido en mito y, como tal, sacralizado. Esta mitología debe ser desmontada para que su "herencia" ideológica, hoy hegemónica en la enseñanza del Diseño 
Gráfico, no siga obturando el desarrollo teórico y práctico de la disciplina.

\section{Introducción}

Un fantasma recorre el mundo del Diseño: la Bauhaus. Muerta, esto es, cerrada en 1932 por decisión del Parlamento (Landtag) de Anhalt (Dessau), su fantasma, como el alma en pena de un cadáver molesto, sigue recorriendo el mundo de la mano de Gropius, sus deudos y colaboradores, "inspirando" programas de enseñanza, lecciones y proyectos en cuanta escuela de arte o diseño se ponga a su alcance, lugares donde su "enseñanza" es repetida, una y otra vez, devotamente, transformada en síntoma, liturgia y coartada.

Canonizada, fetichizada, La Bauhaus debe ser historizada más que invocada o exorcizada. Unicamente analizándola críticamente dentro del contexto histórico que le dio origen y la condenó a muerte, el fantasma volverá a descansar, el síntoma será remitido. Tarea de carácter urgente, sobre todo si se examinan las consecuencias negativas que el culto al mito Bauhaus acarrea en relación a nuestra disciplina, el Diseño Gráfico, que gracias a ese mito no ha logrado hasta ahora afirmar su carácter radicalmente distinto, su diferencia cualitativa con respecto al conjunto de los diseños y continúa ocupando una posición subordinada y menor en la tipología del "Movimiento moderno", encarnado, entre nosotros, por el "pensamiento de la Arquitectura". Intentar desmontar el mito Bauhaus, al tiempo que se pretende dar cuenta de las causas de su perduración, no es tarea sencilla, especialmente si aceptamos, desde la perspectiva freudiana, las raíces inconscientes que alimentan los mitos. Pero además los mitos cumplen una función legitimadora de una situación de poder dada sobre todo cuando, además, están incorporados al imaginario colectivo como parte del "orden natural" de las cosas. Aunque en verdad se trate de un orden histórico.

En la Argentina, como en otros países, con diferencias de tiempo determinadas por ritmos y modalidades diferentes del proceso de acumulación capitalista, el diseño gráfico surge como una práctica social que en un momento dado de su desarrollo, se asume en tanto dominio de conocimiento alcanzado un cierto grado de profesionalización empírica, para luego acceder a las aulas universitarias y entramarse en la trama de las cuestiones del poder y la política.

Es en esta circunstancia de disciplina nueva, sin tradición propia, cuando surge la necesidad de instituir un mito fundador que legitime el naciente saber, la nueva profesión. En un país tecnodependiente como la Argentina -correlato de su condición de país agroexportador-así como el Ejército debió importar el modelo prusiano para la formación de sus cuadros -lo que da cuenta de su germanofilia y su toma de partido durante la II Guerra- los padres fundadores del Diseño gráfico importaron el modelo Bauhaus, paradigma del racionalismo alemán y el Movimimiento moderno: si no hubiera existido la Bauhaus, se la habría inventado, y algo de eso ocurrió.

Mientras el mito bauhausiano no sea removido del lugar totémico que todavía ocupa en nuestros centros de enseñanza, no será posible construir un nuevo paradigma del diseño gráfico, caracterizado hasta hoy por su pobreza teórica como consecuencia de la repetición litúrgica de la "enseñanza" de Bauhaus. En última instancia, la función del pensamiento crítico no es otra que la de cuestionar el dogma teológico: si examinamos los hechos objetivos que constituyeron el fenómeno Bauhaus, si los instalamos en el movimiento de la historia, observaremos cómo se fue construyendo el mito, a que propósitos político-culturales ha obedecido esa construcción y podremos entonces, sin remordimiento, ubicar sus venerables reliquias en el museo. Se trata no sólo de describir el síntoma, sino de erradicarlo.

\section{Realidad y relato de la realidad}

Ya en 1963 Tomás Maldonado, entonces en la Escuela de Diseño de Ulm (Hoschule fur Gestaltung) afirmaba: "la Bauhaus, antes realidad es hoy fábula".(Maldonado, Tomás, 1971:175). Benévolo, Maldonado atribuía el surgimiento de esa fábula a un inevitable proceso, casi didáctico de simplificación: "cuando una realidad es demasiado rica o compleja -y la realidad de la Bauhaus siempre ha sido así- la fábula llega en su ayuda para hacerla más fácilmente legible". Y concluye señalando las diferencias "entre la Bauhaus legendaria y la Bauhaus real (en la correspondencia con Walter Gropius que Maldonado hace pública en el artículo citado, esa diferencia queda clara, incluso desde el propio Gropius). Sólo cabe agregar que el asunto es bastante 
más complejo de lo que Maldonado creía, puesto que el mito Bauhaus no es un mito homogéneo, transparente -como el de Edipo lo fue para la mirada de Freud- por el contrario, está conformado por una serie de mitos menores, cada uno de los cuales puede asumir un rol protagónico según sea el cuestionamiento en particular; más que un mito se trata de un verdadero sistema mitológico, con temáticas y personajes versátiles, ambiguos y cambiantes. Es necesario precisar que nuestra crítica, siguiendo la distinción que establece Maldonado, no va dirigida tanto a la Bauhaus "real" aunque como se verá se trata de "varias" Bauhaus- cuanto a las manipulaciones, deliberadas o no, que desde 1925, por lo menos se vienen practicando sobre esa realidad hasta transformarla en relato legendario.

La cuestión se hace más compleja si se observa que la mitologización o, si se prefiere, "idealización" también alcanza a la República de Weimar en cuyo marco institucional nace y muere Bauhaus, por lo que será necesario ir contextualizando los hechos en relación con el marco histórico en el cual se producen, sin perder de vista, por último pero no menos importante, las consecuencias teóricas y prácticas del mito Bauhaus en el campo de la enseñanza del Diseño gráfico en el ámbito local.

Los estudiosos de las cuestiones relativas a la cultura y la sociedad deberían interrogarse acerca de cómo y por qué un discurso eurocéntrico, autoritario y dogmático, atravesado por estratos profundamente irracionalistas, como es el discurso de la Bauhaus, se ha convertido en discurso hegemónico en nuestras instituciones de enseñanza del Diseño -y sigue perpetuándose. Se presentan a continuación algunos (pocos) de los tantos mitos que se han tejido en torno a Bauhaus, para pasar luego a discutirlos.

\section{Mito 1: “La Bauhaus dió origen institucional al Diseño y al Diseño Gráfico en particular"}

Estos mitos quedan expresados con suma claridad en el documento "El Diseño gráfico y su perfil profesional" publicado por la ADG (Asociación de Diseñadores Gráficos) en 1981, documento que nos ayuda a entender el proceso de autoconciencia que se genera en esa época en el conjunto de diseñadores gráficos en actividad, en su casi mayoría sin formación universitaria específica y provenientes de las más diversas disciplinas y de qué manera se hace presente el "espíritu" bauhausiano.
Tras una larga enumeración de "los momentos de la evolución histórica de la sociedad en los que hubo aportes significativos en el plano de la comunicación visual", el documento sostiene: "La experiencia de Bauhaus dio fin progresivamente, en el nivel educativo, a la concepción artesanal de la producción del diseñador, proveyó al mundo de un repertorio de formas nuevas obtenidas por procesos industriales, enfatizó el objetivo de responder a las necesidades reales de la sociedad y dio nacimiento institucional a nuestra profesión" (ADG, 1981:7)

No hace falta insistir en el carácter laudatorio del párrafo citado: asistimos al momento fundacional del mito en su versión doméstica. Ahora intentemos ir del relato a la realidad. Desde su fundación en Weimar, Turingia, en 1919, la Bauhaus contó con una modesta imprenta dedicada casi exclusivamente a la impresión de grabados, en el espíritu de las "artes gráficas". El tantas veces citado Frontispicio "Catedral" de Lyonel Feininger que ilustraba el Programa de la escuela se imprimió allí. Feininger fue también el primer "maestro de forma" del Taller de Imprenta de Bauhaus. Las primeras experiencias con tipografía, ejercicios de carácter morfológico, fueron programadas por Josef Albers, como colaborador de Lazlo Moholy-Nagy, a cargo del Curso Básico (o curso preliminar o Período de Prueba) Vorkurs, tras la partida de Johannes Itten.

En 1923, al calor de la Primera Exposición Bauhaus el taller despliega una gran actividad, produciendo postales, mapas, catálogos y carteles -entre ellos el muy conocido de Joost Schmidt. Actividad que se incrementa cuando la Casa de la Moneda de Turingia encarga a la escuela el diseño de nuevos billetes por un millón, dos millones y un billón (!) de marcos -recordar que nos encontramos en pleno proceso de hiperinflacióntarea que realiza el entonces "aprendiz" Herbert Bayer, quien también diseña la "invitación" para la fiesta de despedida (la Bauhaus ha sido expulsada de Weimar)

Ya en Dessau (Land de Anhalt) el taller adquiere otra importancia produciendo abundante material gráfico bajo la dirección del ahora "joven maestro" Herbert Bayer, con fuerte presencia de Moholy-Nagy. La actividad del taller se incrementa incluyendo publicidad, diseño de pabellones de exposición, folletos promocionales, avisos y proyectos de identidad visual, contando para ello con equipamiento moderno.

Es en esta etapa cuando se desarrolla el "estilo Bauhaus" en gráfica, caracterizado por el uso sistemático de caracteres sin serif, filetes 
gruesos, composición asimétrica, líneas oblicuas o dispuestas en sentido vertical, que denuncian una marcada influencia de la estética de "De Stijl" y del constructivismo soviético de la época. Siguiendo las ideas de gustavo nagel (con minúsculas) uno de los tantos pintorescos personajes que proliferaron en Bauhaus en la etapa Itten, quien proponía la eliminación de las mayúsculas, Bayer diseña (1925) el alfabeto universal, tipografía construida programáticamente sobre la base de círculos, de carácter experimental y dificultosa lectura. El nombre que Bayer elige para su fallido alfabeto revela como se ubicaban algunos de los integrantes de Bauhaus con respecto al resto del mundo: en su centro.

Conteporáneamente Josef Albers diseña un alfabeto del tipo "stencil", prolija aplicación del programa bauhausiano, construido mediante cuadrados, triángulos y cuartos de círculos, "ejercicio" que todavía se sigue realizando en nuestras facultades- de imposible legibilidad y desequilibrio formal, válido, según los términos de Enric Satué (1998:158) como "inofensivo ejercicio del curso de enseñanza preliminar", pero indigno del rigor teórico de su autor. En síntesis toda la producción de diseño tipográfico de Bauhaus se reduce a dos alfabetos inservibles. El lugar de Bayer, que abandona la escuela tras el nombramiento de Hannes Meyer como director, para dedicarse en Berlín a la actividad profesional (revistas Vogue y Die Neue Linie, agencia Dorland Berlin Studios, afiches para el partido Nazi) es ocupado por Joost Schmidt: el taller de Imprenta es ahora Departamento de Publicidad y ya no está subordinado al Departamento de Arquitectura. Para entonces la tipografía estaba incorporada como materia obligatoria del Curso preliminar.

En este, que es su momento de mayor esplendor, la Bauhaus ha producido 11 libros de la colección Bauhaus Bücher -en su mayoría diseñados por Moholy-Nagy- revistas, gran cantidad de afiches, folletos, catálogos, etiquetas comerciales, aplicaciones gráficas, en edificios, tanto para uso interno de la escuela como para clientes externos- y ha generado una copiosa literatura.

Ahora bien, esta práctica, en tanto tal, ¿es suficiente para afirmar en forma terminante que lo que se está produciendo es efectivamente diseño gráfico? Si por "Diseño gráfico" se entiende: "la disciplina que posibilita comunicar visualmente informaciones, hechos, ideas y valores útiles al hombre, mediante un procesamiento de términos de forma de factores perceptivos, económicos, tecnológicos, ergonómicos y ambientales" (ADG, 1981:7), esto es, como pura manipulación y disposición de formas en el espacio, la producción gráfica de Bauhaus se encuadra en el campo del "diseño gráfico" con toda legitimidad.

Pero si, por el contrario, sostenemos que esta visión del "diseño gráfico" peca de estrecha y formalista puesto que elude deliberadamente la cuestión central del Diseño gráfico, la cuestión de la comunicación, se apreciará mejor por qué nos negamos a reconocer a Bauhaus, a pesar de su esforzada producción gráfica, el carácter fundacional que se le atribuye. Entendemos que la comunicación -aún y especialmente en un subgénero, la trajinada "comunicación visual"no una simple cuestión de "formas" sino un complejo fenómeno subjético e intersubjetivo que se produce en un espacio social atravesado por tensiones de clase, por intermedio de un sofisticado sistema de signos y códigos combinatorios, de carácter artificial, que constituye el lenguaje, que posibilita el intercambio simbólico entre los hombres. Un fenómeno, permítasenos redundar, exclusiva y excluyentemente humano y social, fundante del sujeto y del lazo social.

Desde este perspectiva, "el diseño gráfico será comunicación o no será" -y si es comunicación es en definitiva un hecho lingüístico, un discurso que asume formas visuales a los efectos de alcanzar con mayor eficiencia a interlocutores de carácter masivo, en virtud de la cual rechazamos con energía la existencia autónoma de los llamados "lenguajes visuales".

$Y$ esto es justamente lo que no aparece en Bauhaus: en su frondosa y heterogénea producción teórica no encontramos referencia alguna a la problemática comunicacional, a la cuestión del lenguaje, a la consideración de los procesos de construcción de sentido, a la psicología de las masas: para Bauhaus todo se resuelve "en términos de forma", invocación mágica que no impide que muchas veces, desafortunadamente, las formas sean idénticas a si mismas: el "estilo Bauhaus".

Esta desconsideración a lo comunicacional se produce, además, en un momento particularmente rico en estudios sobre estas cuestiones: Freud, Pavlov y Wilhelm Reich han publicado sus obras fundamentales. El "Curso de Lingüística General" circula por Europa, Peirce ha dado a conocer sus teorías sobre el signo, la Escuela de Chicago ha iniciado sus investigaciones sobre el público y la sociedad, las tesis de J. Dewey y G. H. Mead son divulgadas fuera del mundo académico, Laswell ha publicado "Propaganda 
Techniques in the World Mar", sin mencionar a Comte, Durkheim y Max Weber.

En este sentido no resulta plausible alegar desconocimiento o desinformación (como intenta Gropius con respecto a la pedagogía de Dewey en su correspondencia con Maldonado); parece más honesto admitir que la temática de la comunicación no figuraba entre las preocupaciones de los maestros de Bauhaus, más interesadas en la construcción y en los objetos. Esta gruesa falencia, a partir de la cual la práctica de la enseñanza del diseño gráfico, en tanto "comunicación visual" pierde toda base conceptual, se percibe en las dificultades que evidencias los autores locales enrolados en al teología del "Movimiento moderno" a la hora de intentar definir científicamente el fenómeno comunicacional.

En su conocido manual "Estudio de Diseño" de generalizada lectura por los estudiantes "de diseño", Guillermo González Ruiz arriesga una versión casi seráfica de la comunicación, que hace recordar el trascendentalismo ingenuo de la primera Bauhaus:

“La comunicación es la energía que está en la misma esencia de todo lo que evoluciona: las galaxias, el hombre, en fin, todos los organismos vivos se encuentran en permanente intercomunicación (González Ruiz, Guillermo, 1994:81)

De esta primera caracterización, en la cual "la comunicación" se nos aparece como una esencia metafísica universal (¿la idea platónica?) se pasa sin más trámite al psicologismo:

"hoy no se concibe a la comunicación social como un aspecto de la psicología sino inversamente a ésta como un aspecto de la Comunicación", para deslizarse finalmente al terreno de la biología y la zoología:

"Cada organismo es comunicación. Entre todos los seres vivos hay innumerables códigos de emisión y recepción. Cada especie orgánica se encuentra inmersa en un estado propio y permanente de comunicación, las abejas se comunican de una manera y los delfines de otra, las aves según su especie lo hacen de modos distintos. Cada célula, tejido o sistema orgánico transmite sus señales en forma diferente". (González Ruiz, Guillermo, 1994:82)

Conclusión, si todo es "Comunicación", es imposible aislar el objeto específico, particular de la investigación científica: la comunicación o bien es una sustancia metafísica inasible, o bien un fenómeno físico de emisión-recepción o bien un producto "orgánico" o en fin algo tan banal que hasta las abejas lo practican con éxito. Es en esta empresa, la del vaciamiento conceptual del diseño gráfico -del cual se excluye al sujeto, la sociedad, la historia y la política- donde la "herencia" de Bauhaus ha producido sus efectos más devastadores y duraderos.

Mito 2: “La Bauhaus implementó, en particular en el Curso Preliminar una propuesta original, coherente y articulada, que continua siendo válida"

La contribución pedagógica de Bauhaus, concretamente los métodos que se empleaban en el Vorkurs -producto de los aportes, no siempre coherentes de Itten, Moholy-Nagy, Albers, Klee y Kandinsky- constituye uno de los legados de la "herencia" más alabados y devotamente repetidos. Es también su costado más represivo y autoritario.

Tomás Maldonado (1971) sostiene que la aparente unidad, coherencia y articulación de esta pedagogía es más el resultado de una reelaboración ad hoc efectuada por Albers y Moholy-Nagy en el exilio (la Bauhaus "legendaria") que un producto auténtico de la Bauhaus "real". Mas allá de esta distinción, lo que si puede comprobarse es que tal pedagogía, caracterizada como "original y moderna", reconoce una larga y rancia genealogía. Sus orígenes pueden rastrearse en los ideales humanistas de la llustración, en particular en Jean Jacques Rousseau ("Emile", 1762) que serán desarrolladas y llevados a la práctica docente por Heinrich Pestalozzi, a fines del siglo XVIII y retomadas por Friedrich Froebel, el pionero de los Kindergarten en el siglo XIX. Froebel es el inventor de los "Dones y Ocupaciones", juguetes didácticos que el infante construía a partir de sólidos geométricos elementales en un proceso que iba de lo simple a lo complejo, acompañando el crecimiento físico e intelectual del niño. En este sentido, Froebel anticipa las teorías evolutivas de Jean Piaget. El objetivo de esta formación, que siguiendo una secuencia estrictamente ordenada comenzaba a los dos meses y concluía a los seis años, era proveer al párvulo de un básico "vocabulario de elementos". Vale la pena destacar que la experiencia de los Kindergarten fue prohibida en 1851 por el gobierno de Prusia que les atribuía intenciones "ateas y socialistas" (Abbot Miller, J., 1994:18). Esta prohibición, que prefigura las expulsiones de Weimar y Dessau que sufrirá Bauhaus, no pudo impedir que la experiencia trascendiera las fronteras prusianas y obtuviera buena acogida en el exterior. 
Desde un punto de vista más técnico, Johannes Ramseuer, colega de Pestalozzi propone ("Manual de dibujo", 1821) la idea de las "formas elementales" (Hauptformen) que Bauhaus retomará oportunamente, aunque tamizada por el velo místico que teñía la enseñanza de Itten.

Todos estos antecedentes, entre los cuales no puede faltar el aporte de Johann Wolfgang Goethe, -quien fuera ilustre vecino de Weimar, cuna de la Bauhaus- que incursiona en la teoría sobre el color en "Contribuciones de óptica" ("Beiträge zur Optik", 1791) teoría que ejercerá considerable influencia en los maestros de Bauhaus, todos estos antecedentes, repetimos, convergen, a fines del siglo XIX y comienzos del $\mathrm{XX}$, bajo el común denominador de "educar por el arte, la Acción y el Trabajo", en las propuestas educativas del "movimiento de la escuela activa" (Hans von Mareés, Adolf Hildebrandt), del "movimiento de la escuela activa" (Georg Kerschensteiner), del "activismo" (María Montesori) y del "progresismo" (John Dewey), todos enrolados en el proyecto de una reforma moderna de la educación.

¿En donde radica entonces, la originalidad de la "tradición pedagógica" de Bauhaus? Según Maldonado, a quien seguimos en estas líneas, está en haber intentado "transferir" estas propuestas, pensadas para la educación infantil, a la formación artística y técnica de jóvenes y adultos. (Ante esta afirmación de Maldonado, Gropius, en la correspondencia citada, manifiesta sorpresa y -supuesta-ignorancia: "usted está en un error al relacionar la Bauhaus con las teorías de Dewey. Yo no sabía nada de él antes de venir a este país (se refiere a los Estados Unidos) en 1937". Maldonado se encarga de probar que ya en 1908 Georg Kerschensteiner en su conferencia sobre "EI problema de la educación del pueblo" se había referido a las teorías de Dewey, algo de lo que Gropius, por entonces empleado de el Estudio Beherens, ¡se enteró en 1961!. O dice haberse enterado en esa fecha.

Las tendencias modernizadoras de la enseñanza se potencian en la Alemania guillermina con la profunda reforma educativa que se pone en marcha en los primeros años del siglo: la urgencia de vincular el arte con la industria por medio de la fundación de escuelas de Artes y Oficios (Kunstgewerbeschule) viene de la necesidad política del Imperio por formar los técnicos y profesionales que la industria alemana necesita de inmediato para poder competir en el mercado internacional, espacio en el cual el Reino Unido le lleva una considerable ventaja. (Es sabido cómo en última instancia, esta competencia por los mercados fue una de las causas, si bien no la única, de la Gran Guerra).

Es en estas circunstancias en las que Hermann Muthesius, designado Superintendente de las Escuelas de Artes y Oficios por el Consejo de Comercio Prusiano convoca a arquitectos y artistas para incorporarlos a las direcciones de las nuevas instituciones educativas: Peter Beherens, Hans Poelzig y Bruno Paul toman a su cargo, respectivamente, las Kunstgewerbeschule de Dusseldorf, Breslau y Berlín.

Este es el contexto en el cual Walter Gropius, envía al gobierno de Turingia (Weimar) su conocido "Memorandum" (enero, 1916) proponiendo la fundación de una nueva institución educativa que pueda concretar "la asociación entre el artista, el industrial y el técnico", en el espíritu y la ideología del Deutscher Werkbund, iniciativa que dará origen, tras el armisticio y la proclamación de las "repúblicas alemanas" (1918) a la Statliches Bauhaus de Weimar.

Desafortunadamente la pedagogía activa, liberadora y progresista que Bauhaus hereda degenerará en la práctica concreta en una nueva escolástica, dogmática y autoritaria -que sigue siendo reproducida como tal por sus epígonos, a pesar de su irremediable anacronismo.

\section{Mito 3: "En la Bauhaus se sitúa el origen del Movimiento Moderno, su pensamiento es de orden racional, además propuso la adecuación de la formación y la producción a las exigencias sociales de la época"}

El racionalismo de Bauhaus es cuestionable desde los mismos orígenes de la escuela, su recurrencia medievalista -en línea con el utopismo reaccionario de William Morris se expresa en el nombre elegido por Gropius, que alude tanto a "construcción" (Bau) como a la fraternidad o cofradía de los constructores de la Edad Media- (Bauhutten) gremio del cual surgirá la masonería y la acción de cosechar (Bauen) lo sembrado (Whiford, Frank, 1991:29). Esta raíz místico-expresionista se hace explícita en la xilografía "Catedral" del Frontispicio de Lyonel Feininger. Curiosamente, en 1932, ya en plena ofensiva Nacional-socialista, el "Vülkischer Beobachter" definía a la Bauhaus, en relación a aquella xilografía, como "catedral del marxismo" -sin reparar que la estética nazi, arcaizante y medievalista tenía con la estética 
gótico-expresionista de la primera Bauhaus más de un punto de contacto. (El tema de la "Catedral" ícono antimoderno por excelencia, reaparecerá en los actos de masas del partido nazi [Partido Nacionalsocialista de los Trabajadores Alemanes, NSADP] en Nuremberg en los que la aparición del Führer era acompañada por la aparición de una "catedral de luz" concebida por Albert Speer: un edificio de luz creado por los reflectores de la defensa antiaérea).

En ese contexto fundacional no desentona el delirio "alucinatorio-oriental" (Comunicación 1971:11) de Johannes Itten a cargo, por recomendación de Alma Mahler, a la sazón esposa "virtual" de Gropius, del Vorkurs. Las creencias místicas y esotéricas de Itten estaban inspiradas en la doctrina Mazdaznan, un híbrido seudoreligioso creado por un tipógrafo germano-americano que se hacía llamar doctor O.Z. A. Ha'nish -la "Z" es en referencia a Zaratrusta-. Estas creencias impregnan toda la actividad de Itten en Bauhaus y constituyen el fundamento "filosófico" de su teoría de los contrastes y de su teoría del color, teorías que, absolutamente fuera del contexto seudomístico al que pertenecen aún se siguen enseñando en nuestras escuelas de diseño.

Tampoco desentona en este clima Adolf Meyer, el socio arquitecto de Gropius, adherente a la Teosofía ni menos aún Wassily Kandinsky quien, a pesar de su experiencia soviética y más allá de su publicitada y sospechosa sinestesia, influído por Rudolf Häusser practica la Antroposofía, ni, por última, gustav nagel, ya mencionado, quien "inventa" la eliminación de las letras mayúsculas, imprescindibles en el alemán escrito. Resulta, en verdad, difícil percibir signos de racionalidad en estos personajes, algunos de ellos protagónicos en la vida de Bauhaus. El supuesto cambio que implicó la sustitución de Itten por Moholy-Nagy, ex simpatizante de la experiencia revolucionaria de Bela Kun en la efímera República Soviética Húngara no implica un cambio de fondo en la pedagogía de Bauhaus, a la que Moholy define como: "la sistemización de aquellos intemporales fundamentos biológicos de la expresión que encierran un significado universal"

(Comunicación, 1971:11)

Es sintomático la frecuencia con que la pretensión de dictar leyes universales aparece en el discurso de la escuela.

Desde Adorno y Horkheimer la razón instrumental puede ser entendida como esa voluntad conquistadora y destructiva del género humano por dominar la naturaleza pretendiendo imponerle "leyes" creadas por los hombres, "razón" que lleva en general a la fetichización de la tecnología y al desastre. El "Movimiento Moderno", categoría lábil, evanescente coartada ideológica, que se sustenta en "la fe en la razón" (proposición incompatible por excelencia) inevitablemente deriva en la razón instrumental al quedar fascinado por la tecnología. Ya sea que se lo encare desde su costado más oscuro, gótico y totalitario (el régimen nacional-socialista) ya desde su costado "progresista" y democrático (los regímenes "occidentales") el sueño tecnológico de la modernidad conduce a la catástrofe: o Auschwitz o Hiroshima. Desde esta perspectiva lo que diferencia al lento y doloroso trámite del Holocausto del instantáneo y masivo explosivo nuclear es apenas una cuestión de método, una diferencia técnica. No otra es la lúcida advertencia de Galileo a Andrea (en "Galileo Galilei" de Bertolt Brecht) cuando, sin descon-siderar la necesidad de la "suave violencia de la razón", nos pone en guardia contra su uso como mero instrumento cientificista al servicio de la dominación política o de la dominación del mercado-que vienen, en la actualidad a ser la misma cosa.

Sería injusto atribuir a Bauhaus participación en este debate pero sí es oportuno señalar que en su programa fundacional ya se encuentran presentes los gérmenes de su destrucción en tanto se debate, impotente, en una contradicción irresoluble entre las consignas modernizantes y racionales, en última instancia tayloristas, de los industriales del Deutscher Werkbund y el medievalismo arcaizante, morrisiano, mesiánico, teñido de expresionismo subjetivista que inspira la Bauhaus temprana. Esta contradicción acompañará la historia de Bauhaus y cada uno de sus términos, a su vez, entrará en conflicto con aspectos de la realidad político-social de la República de Weimar que, en un momento dado de correlación de fuerzas determinará su disolución.

\section{La cuestión de la "utilidad social"}

Cierta lectura idealista del Manifiesto fundacional de Bauhaus pretende hacernos creer que "El Diseño" (así, cosificado) existe para satisfacer necesidades humanas "materiales y no mate-riales": en eso consiste su función social. Por supuesto en ningún momento tales "necesidades" son formuladas en los términos específicos del sistema económico concreto de una sociedad en 
particular, por lo que devienen en abstractos, ideales, apolíticos, declaratorios.

Es esta la concepción que subyace a la definición que de "Diseño" proponía la ADG en 1981:

"Diseño es un proceso intuitivo, racional y operativo de creación de formas útiles al hombre..." y que, coherentemente se aplica también a la definición del Diseño gráfico: "la disciplina que posibilita comunicar informaciones, hechos, ideas y valores útiles al hombre..."; ambas afirmaciones se sostienen en la existencia ideal de una utilidad "genérica" para un hombre igualmente "genérico", que existe fuera de la historia y de la sociedad de clases.

Para Gropius la "adecuación a las exigencias sociales" (de la República de Weimar) constituía "la dimensión revolucionaria" de Bauhaus, expresada en la condena explícita al "artista romántico marginado e inútil" y el apoyo a las nuevas exigencias de "productividad y profesionalidad". Esta "dimensión revolucionaria" figuraba ya en el Programa del

Novembergruppe, organización de intelectuales y artistas de izquierda a la que Gropius perteneció y, en las condiciones concretas de la Republica de Weimar, era un programa inviable, como Hannes Meyer lo comprobaría en carne propia en 1930 cuando se vio obligado a renunciar a la Bauhaus (este episodio será examinado más adelante) y como la publicación de izquierda AIZ lo expresara, a propósito de dicha renuncia: "una Bauhaus revolucionaria era una ilusión en un Estado capitalista" (citado por Whitford, Frank, 1991:191) lo que nosotros agregaríamos, en un estado capitalista crecientemente fascistizado.

Con respecto a la cuestión de las "exigencias sociales" que "El Diseño" debería satisfacer, es necesario puntualizar la confusión ideológica y la actitud mesiánica de Gropius, en tanto autor de aquel manifiesto y director de la Bauhaus. Por una parte, toma de los expresionistas alemanes -el Manifiesto está fuertemente influído por el expresionismo- la convicción de que el arte puede, por si sólo, cambiar el mundo, convicción que alcanza su formulación más ambiciosa en el proyecto utópico de Bruno Taut, compañero de ruta de Gropius en las organizaciones culturales de izquierda, según el cual "el Arquitecto podría transformar el mundo y la conciencia de los hombres". Por otra parte ambos, Gropius y Taut, participan de las actividades del Deutscher Werkbund, cuyos objetivos eran eminentemente pragmáticos e inmediatos. Muy pronto, sin embargo, Gropius abandonará la utopía "revolucionaria" y su inicial posición anti-maquinista y anti industrial (ver su discurso de Leipzig, 1919, donde condena "la peligrosa adoración del poder y la máquina que nos conduce desde el abismo espiritual al abismo económico), (Whitford, Frank, 1991:34) para asumir una actitud más "funcional" respecto a las demandas de la industria alemana.

Alrededor de 1920 Gropius se ha alejado definitivamente de las posiciones radicales del Consejo de Trabajadores del arte (Arbeitsrat für Kunst) que se constituye en 1918 al calor de la organización de Consejos de Trabajadores y de Soldados en las primeras fases de la Revolución alemana, para asumir las posiciones más conservadoras del Werkbund más preocupada, desde su fundación en 1907 de mejorar la competitividad de la industria alemana -y la plusvalía a obtener-con el valor agregado del "Diseño", entre cuyos fundadores no podemos omitir a Peter Beherens responsable del diseño "total" de AEG (Allgemeine Elektricitaes Gesellschaft) ni a Henry van de Velde, por entonces director de Kunstgewerbeschule de Weimar en cuyas instalaciones empezaría a funcionar la futura Bauhaus.

El Artetstrat für Kunst del que Gropius formara parte en 1918 en su etapa militante, sostenía una ideología radical y voluntarista: "El Arte y el Pueblo deben formar una unidad", proclama el Manifiesto de fundación, redactado por Bruno Taut, en tanto Gropius afirmaba, en una de las publicaciones del grupo que "la verdadera tarea del Estado socialista es el exterminio del demonio del mercantilismo y lograr que el espíritu activo de la construcción florezca de nuevo entre el pueblo (citado por Whitford, Frank, 1991:38).

Frente a semejante declaración de principios y, más aún, el compromiso personal que Gropius asume al diseñar el Monumento erigido en Weimar a los huelguistas asesinados por la policia "socialista" en marzo de 1921, llama la atención que muchos años después en la ya citada correspondencia con Tomás Maldonado y a propósito de la expulsión de Meyer y de la intervención policial en la Bauhaus de Dessau por pedido expreso de su nuevo director, Mies van der Rohe, "para lograr un mínimo de disciplina", Gropius declare: "mis intereses apenas si rozaban el campo social y usted tiene razón en establecer con esa base uno de sus desacuerdos con mi pensamiento". (Maldonado, Tomás, 1971:190)

Como se ve, del mesianismo arrogante de los orígenes, en los que se proponía la creación de un "hombre nuevo" la Bauhaus se precipita en un blando humanismo resignado -el mismo que campea en las definiciones de ADG antes 
citadas- que se conforma con predicar la

"humanización de la tecnología y el

capitalismo".

En síntesis, lo que ni Gropius ni la Bauhaus llegan

a comprender-incomprensión radical que los

"herederos" locales comparten y repiten

devotamente en orden a la "utilidad" del

diseño-es que "sin el control efectivo de los

medios de producción, la intervención del artista

(o del diseñador) en la industria, reinvindicada

por la vanguardia revolucionaria, no es sino

dependencia de los intereses de la clase

dominante". (Comunicación, 1971:10)

\section{Mito 4: "La politización de Bauhaus, promovida por su director, Hannes Meyer, fue la causa de la clausura"}

En enero de 1928 Walter Gropius renuncia a la dirección de Bauhaus proponiendo como sucesor al arquitecto Hannes Meyer; esta decisión motivó la inmediata renuncia de Moholy-Nagy, seguidas por las de Marcel Breuer y Herbert Bayer. Llama la atención que las renunciantes en la carta que envían al Consejo de Profesores justifican su decisión, un tanto anacrónicamente, en su condición de "revolucionarios":

"rechazamos una escuela de formación vocacional que evalúa únicamente el resultado final y no presta atención al desarrollo de la totalidad de la persona; el espíritu comunitario se sustituye por la competitividad individual" (Whitford, Frank, 1991:185)

Bajo la dirección de Meyer la Bauhaus asume por fin, a nueve años de su fundación, su carácter de Escuela de Arquitectura. Esta se organiza en dos áreas, Teoría y Práctica de la construcción y Diseño Interior, que comprende también el diseño de muebles y utensillos; todos los talleres, ahora "Laboratorios" quedan subordinados a la Escuela de Arquitectura, a excepción, como antes se indicó del flamante y cada vez más activo Departamento de Publicidad (Joost Schmidt), el laboratorio de Teatro-que posteriormente será cerrado tras la renuncia de Oskar Schlemmer-y las clases de pintura a cargo de Klee y Kandinsky.

La nueva orientación que impone Meyer incluirá en la currícula materias que eran normales en las escuelas de arquitectura de la época y que Bauhaus no impartía, como Planificación Urbana, que dictará Ludwig Hilbersheimer. Además se instala un nuevo taller de Fotografía (Walter Peterhaus), la escuela contrata a profesores invitados que dictan cursos de Sociología, Teoría política marxista, Física,
Ingeniería, Psicología y Economía; un verdadero centro universitario que, además, está volcado al diseño y producción de artículos prácticos y económicos destinados a la producción en serie. El auge económico que la República experimenta en esos años garantiza un mercado en crecimiento.

En este marco se realizan contratos con la fábrica de papeles para decoración de Emil Rasch a partir de diseños realizados en el laboratorio de pintura mural, se producen artefactos eléctricos para las piscinas de Dessau y para el Museo de Higiene de Dresde, así como accesorios y mobiliario para las ferias comerciales de Dessau y Leipzig; el Diseño Industrial, como disciplina autónoma adquiría su definitivo perfil profesional. Además el Departamento de Publicidad firmaba un importante contrato con IG Farben, una de las concentraciones industriales más poderosas de Alemania, que cubría el $50 \%$ de la industria química, todo lo cual colocaba a la Hoschule fur Gestaltung (Instituto de la Forma o del Diseño) el nuevo nombre de la Bauhaus de Dessau, por primera vez en su corta historia, a punto de autofinanciarse -contaba para ello con su propia compañía comercial, fundada con el aporte económico de Adolf Sommerfeld, el comitente berlinés de la casa expresionista diseñada por Gropius en 1921, que se encargaba de comercializar las patentes y los productos del instituto; autofinanciación que le hubiera posibilitado prescindir del políticamente riesgoso patronazgo estatal; y más en la convulsionada Alemania de la época.

Todos los testimonios coinciden en que entre 1928 y 1930, bajo la dirección del "marxista" Meyer y gracias a una coyuntura económicamente favorable, Bauhaus, por primera vez, estaba cumpliendo en el propósito para el cual había sido fundada: contribuir al desarrollo capitalista de la "nueva" Alemania de posguerra colaborando, desde el Diseño, en la producción de artículos de buena calidad y bajo costo.

Está claro que ya no se trata de la Bauhaus "expresionista" y "mística" de Itten, ni de la Bauhaus "constructivista" de Moholy-Nagy, sino de una nueva Bauhaus, verdaderamente moderna, racional e industrialista, más volcada a la eficacia y a la productividad que a estériles devaneos teóricos sobre "la amarillez del triángulo", a esa altura francamente anacrónicos-digo, en 1928. Y está claro, por último que ante este nuevo rumbo los sobrevivientes de la "era Gropius" no se sentían demasiado cómodos, a decir verdad, se sentían sumamente incómodos por diversos motivos: el 
énfasis que se ponía en la construcción -cosa que sorprende puesto que este era el objetivo original y principal de la escuela; - la importancia que se daba a la publicidad -en general los adictos del "Movimiento Moderno" profesan una sorda hostilidad a la Publicidad que, para su visión maniquea representa el lado "malo" del diseño y la comunicación visual-; $y$, finalmente, no compartían el enfoque sociológico desde el cual se abordaban las distintas temáticas y proyectos. A partir de ese malestar, la vieja guardia trascendentalista y subjetivista tratará de deshacerse de Meyer; la política servirá como pretexto y Kandinsky se encargará de montar la intriga.

Es cierto que hacia 1930 la política ocupaba un lugar en Bauhaus, se impartían cursos de teoría política, se había organizado una pequeña pero activa célula del Partido Comunista Alemán (KDP). En los Carnavales de 1930 el coro de la escuela había tenido la osadía de interpretar canciones revolucionarias rusas, hechos que pueden hoy parecer banales pero que en aquellas condiciones de extrema tensión política, fueron rapidamente aprovechados por la oposición de derecha de Turingia - hasta entonces gobernada por la socialdemocracia (SPD) para acusar al Instituto de ser "un nido de bolcheviques".

\section{Contexto histórico de la República de Weimar, 1928-1933}

Resulta inevitable describir el contexto histórico de Alemania en estos años. La crisis económica mundial, consecuencia del "crack" de la bolsa de Nueva York en 1929, empieza a manifestarse con el retiro de los capitales extranjeros, la deflación y el desempleo. La breve prosperidad de 1928/29 ha llegado a su fin; el total de parados, que en septiembre de 1929 sumaba 1.300.000 había aumentado un año después a 3 millones -y seguirá subiendo hasta llegar a más de 5 millones en 1932: el 44,4 por ciento de la fuerza de trabajo.

En el aspecto político, concretamente en las elecciones del 14 de septiembre de 1930, mientras el todavía mayoritario partido socialdemócrata (SPD) veía disminuir sus votos en más de medio millón -tendencia declinante que se mantendría hasta las elecciones del 6 de noviembre de 1932, las últimas que realizará la República- sus "enemigos" (el mito de la "doble amenaza" a la frágil República democrática será examinado en otro lugar) de izquierda y de derecha aumentan su caudal de votos: por un lado el Partido Comunista (KPD) acusa un moderado crecimiento (de 3.265 .000 obtenidos en las elecciones del 20 de mayo de 1928, pasa a obtener 4.592.000) pero por el otro lado, el Partido nazi (NSDAP) experimenta un crecimiento verdaderamente extraordinario: de apenas 810.000 votos en 1928 pasa a cosechar 6.383.000 que lo convierten en el segundo partido de la República (a la cual odia visceralmente). La tendencia creciente continuará, en 1932 alcanzará 13.769 .000 votos, muy por delante del SPD y del KPD.

La lucha de clases que en los meses posteriores a la Revolución de Noviembre había adquirido la forma de "guerra civil" asumía de nuevo una extrema dureza. Las Secciones de Asalto (Sturm Abteilung o SA) y las Cuadrillas de Protección (Schutz Staffel o SS) los brazos armados del nazismo, comandados por Ernst Röhm y Heinrich Himmler, respectivamente, imponían en las calles el terrorismo político, ante la mirada tolerante de las autoridades.

En este clima de extrema tensión política donde el futuro inmediato de la República parecía ser o un golpe de estado del Reichswehr o el inevitable acceso del nazismo al poder, resulta explicable la "politización" y aún la radicalización de amplios sectores de la población; en este contexto la "politización" de Bauhaus era poco menos que inevitable, no era tiempo para apolíticos ni indiferentes cuando la República estaba al borde de la disolución. Este es el momento que Kandinsky aprovecha para forzar la expulsión de Meyer.

Whitford (1991:191) le dice sin ambages:

"Kandinsky estuvo claramente implicado en una conspiración para deshacerse de Meyer". Para conseguirlo utilizó los buenos oficios del crítico de arte Ludwig Grote quien se encargó de denunciar ante Fritz Hesse, el burgomaestre de Dessau, la desviación politizante en que había caído el Instituto, copado por peligrosos "radicales de izquierda", con la complicidad de su director.

El pretexto formalmente utilizado para su expulsión fue deleznable: la solidaridad que el Instituto había hecho llegar a mineros en huelga donando dinero para el fondo sindical. El Consejo de Profesores aceptó por mayoría la "renuncia" de Meyer, con excepción de Gunta Stolzl y de Paul Klee, más preocupado entonces por encontrar un puesto cómodo en otra institución.

Walter Gropius no fue ajeno a esta maniobra. Años después, en su Correspondencia con Tomás Maldonado, se autojustifica: "Desde la experiencia de Weimar estaba firmemente convencido de que la intromisión de la actividad 
política en el interior del Instituto acabaría con

él". Considera que la actividad de Meyer

"convulsionó la idea de la Bauhaus y llevó al Instituto a una situación comprometida" para concluir con un juicio tajante y, curiosamente, 'político': "Tanto su estrategia como su táctica eran demasiado restringidas; era un radical pequeñoburgués". (Maldonado, Tomás; 1971:189,190).

Desde 1930, a partir de su "excomunión", el nombre de Hannes Meyer quedó definitivamente demonizado para el "Movimiento moderno" que trata de tender sobre su gestión al frente de Bauhaus, la más fructífera de su historia, un velo de sombras.

\section{El verdadero epílogo}

Pero Bauhaus sobreviviría a la "politización" y la expulsión de Meyer dos años más. Ludwig Mies van der Rohe, antiguo compañero de Gropius en el estudio Beherens y autor del monumento a Karl Liebknecht y Rosa Luxemburg los líderes de la Liga espartaquista (Spartakus Bund) asesinados en enero de 1919, se hace cargo del Instituto en agosto de 1930, con el objetivo inmediato de restablecer la "reputación" de Bauhaus volviendo a la tradición de la prescindencia política. Consecuente con el humanismo abstracto del pensamiento "liberal" para imponer el orden recurrirá a la represión. A la expulsión de Meyer seguirá la de los estudiantes comunistas. Ante la protesta estudiantil que lo sindican de "formalista" y de dedicarse a construir casas para ricos, a la vez que exigen la continuidad de los cursos de Sociología, Economía y Psicología, van der Rohe responde solicitando la intervención policial y clausurando temporalmente el Instituto; después de que la Bauhaus fuera cerrada en Weimar por la presión de la mayoría derechista en el Landtag de Turingia, es la primera vez que la Bauhaus se clausura a si misma por decisión de su director.

Antes de reabrir la escuela para reiniciar el año lectivo de 1931 -todo el "affaire" Meyer se ha tramitado en el período de vacaciones de verano- van der Rohe cita a los estudiantes "uno por uno" para advertirles que serán expulsados si no obedecen las nuevas normas que incluyen la absoluta prohibición de actividades políticas y envía a cada estudiante una "declaración" que deberá firmar para ser readmitido:

"El firmante se compromete a asistir a los cursos regularmente; a no permanecer en la cantina más tiempo que el que dure la comida, a no acudir a la cantina por la noche, a evitar las discusiones políticas, a no causar molestias en la ciudad, y a salir a la calle bien vestido"

(Whitford, Frank, 1991:193).

La intolerancia, en sí misma una actitud fascista, se ha instalado en Bauhaus.

Bajo la dirección de van der Rohe que alterna su función en Dessau con la atención de su Estudio en Berlín, entonces abocado de la célebre Casa Tugendhat en Brno, Checoeslovaquia, Bauhaus se convierte en una Escuela de arquitectura tradicional, con fuerte acento en lo teórico y en las cualidades formales de los proyectos, en tanto la práctica productiva de los Talleres va declinando hasta su virtual paralización. En una coyuntura económica cada vez más crítica y en un contexto político cada vez más opresivo, Bauhaus inica un proceso de lenta pero irresistible erosión que conducirá a su muerte. Tras la renuncia de Gunta Stolzl y de Paul Klee que por fin ha logrado su ansiado "puesto cómodo" en la Academia de Arte de Duseldorf, de la "era Gropius" sólo sobrevive Kandinsky en una función casi decorativa de subdirector, puesto que su asignatura de pintura ha sido suprimida. Años después Hannes Meyer (Bauhaus Dessau, publicado en "Edificación" N³4, México, 1940) realiza su propio balance respecto a la etapa terminal de Bauhaus:

"La influencia de los estudiantes en el estilo de vida de la Bauhaus fue borrada. Todos los temas sociológicos desaparecieron, especialmente en la actividad de los laboratorios. Otra vez ingresaron los hijos de las clases altas como estudiantes y en los laboratorios se producían muebles de lujo con materiales suntuarios. Entre los estudiantes aparecieron los primeros nazis organizados" (Whitford, Frank, 1991:193 y Nicolini, Renato, 1971:164).

Mientras tanto en la República de Weimar se producía la desintegración final del sistema democrático, el Reichstag se encontraba prácticamente paralizado y, haciendo uso de las facultades que el artículo 48 de la Constitución le permitía, el presidente Hindemburg, reelecto en 1930 con el apoyo de la socialdemocracia, gobernaba mediante decretos. La Socialdemocracia (SPD) se debatía ante su impotencia para movilizar a las masas y hacer frente a la marea nazi y la insalvable hostilidad que la oponía al Partido Comunista (KPD) desde el sangriento aplastamiento dirigido por Gustav Noske de la asonada espartaquista de 1919, hacía inviable cualquier intento por organizar un Frente de izquierda, además el KPD, en la línea sectaria que imponía la III Internacional, veía en 
la Socialdemocracia, caracterizada como "socialfascismo" su enemigo principal.

Después de las elecciones para el Reichstag de noviembre de 1932 en las que el NSDAP obtiene la mayoría, Hindenburg resuelve el impasse designando a su lider Adolf Hitler Canciller del Reich, el 30 de enero de 1933, sellando así la muerte de la República de Weimar.

Dos años antes, en 1931, el NSDAP había conseguido la mayoría en el Landtag de Anhalt, cuya capital Dessau hospedaba a Bauhaus y al año siguiente, invocando pretextos por demás banales (la cuestión de los "tejados planos", el "cosmopolitismo", su estilo "frío y racional" contrario al espíritu alemán, etc.) suspendía la subvención que otorgaba a la escuela y rescindía los contratos de los profesores. El 30 de septiembre de 1932 Bauhaus cierra sus puertas definitivamente. La prolija prescindencia política de van der Rohe no había dado resultado; convertida para la peculiar visión nacionalsocialista en símbolo de la Kulturbolschewismus, sin pena ni gloria la Bauhaus de Dessau también había muerto. NOTA: La "Bauhaus" que a finales de 1932 Mies van der Rohe estableció en Stegliz, Berlín, fue un emprendimiento de carácter privado que iba a ser solventado con las cuotas de los alumnos y el usufructuo de las patentes de la legítima Bauhaus.

Por lo tanto su clausura, el 11 de abril de 1933 por la Policía de Berlín no puede ser vinculada a la historia de la Bauhaus estatal.

La violencia nazi no justificó, sin embargo, la hábil instrumentación política que Gropius y sus seguidores hicieron de este episodio para instalar el mito (otro más) del martirologio de Bauhaus, que alcanzó repercusión internacional, estimulado más tarde por la emigración.

Sobre las negociaciones que por entonces van der Rohe mantuvo con el Presidente de la RKK (Reichchskulturkammer o Cámara de Cultura del Reich) doctor Joseph Goebbels, nos extenderemos en otro lugar.

\section{Bibliografía}

Abbot Miller, J.

(1994), Escuela elemental. En: El abc de la Bauhaus y la teoría del diseño. Ellen Lupton y J. Abbot Miller (eds.). Barcelona, Gustavo Gili.

ADG (Asoc. de Dis. Gráficos de Buenos Aires) (1981), El diseñador gráfico y su perfil profesional. Buenos Aires, ADG
AA. VV.

(1971), Comunicación, Prólogo: La Bauhaus, Comunicación 12. Madrid, Alberto Corazón Editor.

González Ruiz, Guillermo

(1994), Estudio de Diseño. Buenos Aires, Emecé Editores.

Maldonado, Tomás

(1971), Otra vez la Bauhaus. En: La Bauhaus, Comunicación 12. Madrid, Alberto Corazón Editor.

Nicolini, Renato

(1971), Mies, el epílogo. En: La Bauhaus, Comunicación 12. Madrid, Alberto Corazón Editor.

\section{Satué, Enric}

(1998), El diseño gráfico desde sus orígenes hasta nuestros días. Madrid, Alianza Forma.

\section{Whitford, Frank}

(1994), La Bauhaus. Barcelona, Ediciones Destino.

\section{Bibliografía complementaria}

- Sobre Europa y la República de Weimar

\section{Arendt, Hannah}

(1982), Orígenes del totalitarismo. Volumen 3; Totalitarismo. Madrid, Alianza Editorial.

Ferro, Marc

(1992), La Gran Guerra, 1914-1918. Madrid, Alianza Editorial.

\section{Herf, Jeffrey}

(1990), El modernismo reaccionario. Tecnología, cultura y política en Weimar y el Tercer Reich. México, Fondo de Cultura Económica.

Hobsbawm, Eric

(1998), Historia del siglo XX, Capítulo VI: Las artes, 19141945. Buenos Aires, Crítica.

Jünger, Ernst

(1995), Tempestades de acero. Barcelona, Tusquets Editores.

\section{- Sobre Bauhaus, arte y comunicación}

Adam, Peter

(1992), El Arte del Tercer Reich. Barcelona, Tusquets Editores.

\section{Anikst, Mikhail}

(1989) Diseño Gráfico Soviético años 20, Barcelona, Ediciones Gustavo Gili.

\section{Argan, Giulio Carlo}

(1983), Walter Gropius y la Bauhaus,Barcelona, Ediciones Gustavo Gili.

Droste, Magdalena

(1996), Bauhaus Archiv 1919-1933. Köln, Taschen.

Mattelart, Armand y Mattelart, Michéle

(1997), Historia de las teorías de la comunicación. Buenos Aires, Paidós Comunicación. 


\section{Muñoz Blanca}

(1989), Cultura y comunicación. Barcelona, Barcanova.

\section{Valdés, Gustavo}

(1991), Poesía y psicoanálisis: un boceto inconcluso. En: Baudes de Moresco, M. y colaboradores: Grupos operativos, Buenos Aires, Ediciones Nueva Visión.

\section{Wingler, Hans}

(1975), La Bauhaus. Weimar, Dessau, Berlín: 1919/1933. Ediciones Gustavo Gili, Barcelona. 